\title{
In Situ Characterization of Elusive Salt Hydrates-The Crystal Structures of the Heptahydrate and Octahydrate of Sodium Sulfate
}

\author{
Iain D. H. Oswald, ${ }^{,+\dagger}$ Andrea Hamilton, ${ }^{\ddagger}$ Christopher Hall, ${ }^{\ddagger}$ William G. Marshall,, \\ Timothy J. Prior," and Colin R. Pulham ${ }^{\dagger}$ \\ School of Chemistry and Centre for Science at Extreme Conditions, University of Edinburgh, \\ The King's Buildings, West Mains Road, Edinburgh, EH9 3JJ, U.K., School of Engineering \& \\ Electronics, University of Edinburgh, The King's Buildings, Edinburgh, EH9 3JL, U.K., ISIS \\ Neutron and Muon Facility, STFC Rutherford Appleton Laboratory, Harwell Science and \\ Innovation Campus, Didcot, OX11 OQX, U.K., and Synchrotron Radiation Source, STFC \\ Daresbury Laboratory, Warrington, Cheshire, WA4 4AD, U.K.
}

Received July 14, 2008; E-mail: iain.oswald@ed.ac.uk

\begin{abstract}
An important intermediate phase in the crystallization of aqueous solutions of sodium sulfate is the highly metastable sodium sulfate heptahydrate $\left(\mathrm{Na}_{2} \mathrm{SO}_{4} \cdot 7 \mathrm{H}_{2} \mathrm{O}\right)$. This has been structurally characterized for the first time by in situ single crystal X-ray diffraction. The crystal structure shows that each sodium cation is octahedrally coordinated to water molecules, with a slight distortion due to one of the water molecules being disordered. The hydrated sodium cations are hydrogen-bonded to form a three-dimensional bonded network, which is markedly different from the architecture of one-dimensional bonded chains observed in sodium sulfate decahydrate (mirabilite). This major structural difference explains the reconstructive nature of the transformation observed between the heptahydrate and mirabilite. High-pressure crystallization of a $3.41 \mathrm{~mol} / \mathrm{kg}$ water aqueous solution of sodium sulfate at $1.54 \mathrm{GPa}$ in a diamond-anvil cell resulted in the formation of a previously unknown sodium sulfate hydrate, which we have determined by single crystal X-ray diffraction methods to be an octahydrate, $\mathrm{Na}_{2} \mathrm{SO}_{4} \cdot 8 \mathrm{H}_{2} \mathrm{O}$. In this structure the sulfate ions are coordinated directly to sodium ions. This resembles anhydrous sodium sulfate (thenardite) but contrasts with the heptahydrate and decahydrate in which the sodium ions are coordinated exclusively by water molecules. This observation demonstrates how the delicate balance of inter- and intramolecular bonds in the crystal structure can be significantly altered by the application of pressure.
\end{abstract}

\section{Introduction}

Sodium sulfate is a salt of great geochemical and environmental importance and is one of the world's major commodity chemicals. ${ }^{1}$ Two well-characterized forms are found under ambient conditions in nature: the anhydrous mineral, thenardite, and the decahydrate known as mirabilite or Glauber's salt. A further three high-temperature forms of the anhydrous salt have been structurally characterized. ${ }^{2}$ In the presence of a saturated aqueous solution of sodium sulfate, the decahydrate is the stable phase at temperatures below $32.4{ }^{\circ} \mathrm{C}$ and is a major component in lacustrine brines such as those found in Saskatchewan in Canada. The decahydrate has also been found as inclusions in deep Antarctic ice cores. ${ }^{3}$ At higher temperatures mirabilite can

† School of Chemistry and Centre for Science at Extreme Conditions, University of Edinburgh.

School of Engineering \& Electronics, University of Edinburgh.

$\$$ STFC Rutherford Appleton Laboratory.

"STFC Daresbury Laboratory.

(1) Sodium Sulfate: Handbook of Deposits, Processing, Properties, and Use; Garrett, D. E., Ed.; Academic Press: San Diego, CA, 2001.

(2) Rasmussen, S. E.; Jørgensen, J.-E.; Lundtoft, B. J. Appl. Cryst. 1996, $29,42-47$.

(3) (a) Ohno, H.; Igarashi, M.; Hondoh, T. Earth Planet. Sci. Lett. 2005, 232, 171-178. (b) Ohno, H.; Igarashi, M.; Hondoh, T. Geophvs. Res. Lett. 2006, 33, L08501. be dehydrated to thenardite, and so the anhydrous form is generally found in arid environments such as the SommaVesuvius complex near Mount Vesuvius, Italy. There is also evidence to suggest that sodium sulfate and its hydrates may be found on Jupiter's satellite Europa. ${ }^{4}$ This has important implications for geological activity on Europa since the lower thermal conductivities of such hydrated salts compared to water ice would be expected to produce steeper thermal gradients. ${ }^{5}$

The crystallization of salts such as sodium sulfate in the pores of stones and cements can cause severe degradation of these materials. Such salt damage causes significant harm to buildings and monuments of cultural heritage and sodium sulfate is widely considered to be one of the most destructive of salts ${ }^{6}$ and so it has been used as an agent for accelerated durability testing of building materials. Crystallization of mirabilite also finds applications in the storage of low-grade solar heat. ${ }^{7}$ Despite the importance of the sodium sulfate/water system there remains

(4) (a) Grundy, W. M.; Buratti, B. J.; Cheng, A. F.; Emery, J. P.; Lunsford, A.; McKinnon, W. B.; Moore, J. M.; Newman, S. F.; Olkin, C. B.; Reuter, D. C.; Schenk, P. M.; Spencer, J. R.; Stern, S. A.; Throop, H. B.; Weaver, H. A. Science 2007, 12, 234-237. (b) Dalton, J. B.; Prieto-Ballesteros, O.; Kargel, J. S.; Jamieson, C. S.; Jolivet, J.; Quinn, R. Icarus 2005, 177, 472-490. (e) Hall, C.; Hamilton, A.; Icarus 2008, $198,277-299$.

(5) Prieto-Ballesteros, O.; Kargel, J. S. Icarus 2005, 173, 212-221. 
considerable uncertainty about not only the crystallization processes, but also the identity of a metastable hydrate that was first described by Loewel in 1850 and which has eluded all subsequent attempts at structural characterization. Loewel's first gravimetric measurements suggested that this was an octahydrate, ${ }^{8}$ but subsequent refinement in experimental method led him to conclude that it was in fact a heptahydrate. ${ }^{9}$ There are also several detailed accounts which show that mirabilite rarely forms directly from supersaturated aqueous solutions on cooling, but that the first solid to crystallize is the metastable heptahydrate. ${ }^{6,10}$ A powder X-ray diffraction pattern assigned to a heptahydrate has been reported in the JCPDS database (card no. 40-0727), but is flagged as being of "questionable" quality. This card is referenced to a short report by Mehrotra, ${ }^{11}$ but contains no details of sample preparation for X-ray analysis. More recent indirect evidence for the existence of the heptahydrate comes from a study by Rijniers et al. in which the authors were able to estimate dissolved salt concentrations from ${ }^{23} \mathrm{Na}$ NMR measurements during the crystallization of sodium sulfate from supersaturated solutions in porous materials. ${ }^{6}$ Dissolved salt concentrations were higher than would be expected if the solution were in equilibrium with mirabilite, but they corresponded closely to the reported solubility of the heptahydrate. ${ }^{12}$ Genkinger and Putnis have investigated recently the crystallization of sodium sulfate both by evaporation of water and by rehydration of thenardite. ${ }^{13}$ They provided X-ray powder diffraction data for a phase that precipitated when thenardite was exposed to a humid atmosphere, and which did not resemble thenardite, mirabilite, or the so-called heptahydrate recorded on JCPDS card no. 40-0727. The authors tentatively indexed the diffraction pattern of this phase to a monoclinic unit cell and named it "selmaite". A very recent paper describes an updated phase diagram for the $\mathrm{Na}_{2} \mathrm{SO}_{4}-\mathrm{H}_{2} \mathrm{O}$ system based on thermodynamic data for aqueous sodium sulfate and the various solid phases. The authors discussed the crystallization pathways and the crystallization pressures generated by these solids in common laboratory weathering experiments and under field conditions. ${ }^{14}$

Our interest in the $\mathrm{Na}_{2} \mathrm{SO}_{4} / \mathrm{H}_{2} \mathrm{O}$ system arises primarily from a desire to understand the crystallization processes and phases responsible for damage to porous materials. In particular, we are interested in the possible role of the metastable heptahydrate in such salt damage. We also wish to develop and apply in situ techniques to characterize such highly metastable solid forms that have only a transient existence under normal conditions of

(6) (a) Hamilton, A.; Hall, C.; Pel, L. J. Phvs. D 2008, 41, 212002. (b) Rodriguez-Navarro, C.; Doehne, E.; Sebastian, E. Cem. Concr. Res. 2000, 30, 1527-1534. (c) Scherer, G. W. Cem. Concr. Res. 1999, 29 , 1347-1358. (d) Espinosa, R. M.; Scherer, G. W. Environ. Geol. 2008, 56, 605-621. (e) Correns, C. W. Discuss. Faradav Soc. 1949, 5, 267271. (f) Flatt, R. J.; Steiger, M.; Scherer, G. W. Environ. Geol. 2007, 52, 221-237. (g) Rijniers, L. A.; Huinink, H. P.; Pel, L.; Kopinga, K. Phvs. Rev. Lett. 2005, 94, 07553. (h) Steiger, M. J. Crvst. Growth 2005, 282, 455-469. (i) Steiger, M. J. Crvst. Growth 2005, 282, 470481 .

(7) Marliacy, P.; Solimando, R.; Bouroukba, M.; Schuffenecker, L. Thermochim. Acta 2000, 344, 85-94.

(8) Loewel, H. Ann. Chim. Phys. 1850, 29, 62-117.

(9) Loewel, H. Ann. Chim. Phys. 1851, 33, 334-337.

(10) (a) Hartley, H.; Jones, B. M.; Hutchinson, G. A. J. Chem. Soc. 1908, 93, 825-833. (b) de Coppet, L. C. Bull. Soc. Vaudoise Sci. Nat. 1901, $37,455-462$

(11) Mehrotra, B. N. Acta Crystallogr. 1987, A43, C119.

(12) Gmelin, L. Handbuch der Anorganischen Chemie; Berlin, 1966; Vol. 21.

(13) Genkinger, S.; Putnis, A. Environ. Geol. 2007, 52, 295-303.

(14) Steiger, M.; Asmussen, S. Geochim. Cosmochim. Acta 2008, 72, 42914306. temperature and pressure. In agreement with earlier work, our studies have shown that cooling a highly concentrated (3.41 $\mathrm{mol} / \mathrm{kg}$ ) aqueous solution to temperatures below $296 \mathrm{~K}$ produces transparent prismatic crystals that persist provided that the contents are kept in a sealed bottle to prevent evaporation and are not cooled below about $273 \mathrm{~K}$. If these conditions are not maintained, then a rapid transformation to mirabilite is often observed. Despite these difficulties, we recently obtained gravimetric data from crystalline material carefully extracted from the mother liquor that strongly supports Loewel's conclusion that this metastable form is indeed the heptahydrate. ${ }^{15}$ The difficulties associated with drying, grinding, and preserving a polycrystalline sample of the heptahydrate preclude the use of conventional powder X-ray diffraction methods. For this reason, we turned in the first instance to in situ energy dispersive $\mathrm{X}$-ray powder diffraction from a stirred suspension of the heptahydrate contained in a sealed, cylindrical, glass bottle. This procedure removed the need to manipulate the sample once crystallites had formed. Using hard X-rays at the U.K. Synchrotron Radiation Source, a sufficiently good powder pattern was obtained to allow indexing and assignment of a probable space group (tetragonal, $a=b=7.1668 \AA, c=22.2120 \AA, I 4_{1} / a$ ). ${ }^{15}$ This did not correspond to either mirabilite or thenardite, or to the pattern described in the JCPDS database. It did, however, closely resemble the pattern described by Genkinger and Putnis for "selmaite" ${ }^{13}$ once adjustment had been made for zero-point errors arising presumably from misalignment of their sample.

In this paper we show how in situ crystallization methods have been used to prepare and characterize structurally both the elusive heptahydrate and an entirely new octahydrate formed at elevated pressure.

\section{Experimental Section}

General. A $3.41 \mathrm{~mol} / \mathrm{kg}$ water sodium sulfate solution was prepared by dissolution of AR grade anhydrous sodium sulfate (Sigma-Aldrich) in deionized water at $313 \mathrm{~K}$. This solution was used for crystallizations at both ambient and elevated pressures.

Crystallization Procedure at Ambient Pressure. The $3.41 \mathrm{~mol} /$ $\mathrm{kg}$ water aqueous solution was loaded into a capillary (o.d. 0.3 $\mathrm{mm}$ ) and warmed to dissolve all of the crystallites. The capillary was mounted on the goniometer of the laboratory diffractometer equipped with a low-temperature device and was cooled to $277 \mathrm{~K}$. After a period of $30 \mathrm{~min}$, no crystallization had occurred so the temperature was ramped at $100 \mathrm{~K} / \mathrm{h}$ to $263 \mathrm{~K}$ and then to $283 \mathrm{~K}$ before returning to $277 \mathrm{~K}$. This temperature cycling induced crystallization of the heptahydrate. Data were collected at 277 and $150 \mathrm{~K}$.

Crystallization Procedure at High Pressure. The $3.41 \mathrm{~mol} / \mathrm{kg}$ water solution was loaded at $293 \mathrm{~K}$ into a Merrill-Bassett diamondanvil cell ${ }^{16}$ equipped with $600 \mu \mathrm{m}$ culet diamonds and a tungsten gasket. The cell was sealed and then warmed so that no seed crystals of an ambient form were present. The pressure was increased to $1.54 \mathrm{GPa}$ to induce precipitation and the temperature was then cycled near $373 \mathrm{~K}$ to dissolve all but one of the crystallites. On cooling to $293 \mathrm{~K}$ the crystallite grew into a larger single crystal. The pressure within the gasket hole was determined by measuring the fluorescence from a small piece of ruby on excitation with a $441.4 \mathrm{~nm}$ line from a $\mathrm{Hg}-\mathrm{Cd}$ laser. ${ }^{17}$ The ruby fluorescence was dispersed and detected by a Jobin-Yvon LabRam 300.

Crystal Data. The X-ray intensities for the octahydrate were collected on a Bruker-Nonius APEX II diffractometer at $293 \mathrm{~K}$ at

(15) Hamilton, A.; Hall, C. J. Anal. At. Spectrom. 2008, 23, 840-844.

(16) Merrill, L.; Bassett, W. A. Rev. Sci. Instrum. 1974, 45, 290-294.

(17) Piermarini, G. J.; Block, S.; Barnett, J. D.; Forman, R. A. J. Appl. Phys. 1975, 46, 2774-2780. 
Table 1. Selected Bond Lengths and Angles for Sodium Sulfate Heptahydrate (Distances in $\AA$, Angles in deg) ${ }^{a}$

$\begin{array}{ll}\mathrm{Na} 1-\mathrm{O} 1 & 2.5094(16) \\ \mathrm{Na} 1-\mathrm{O} 2 & 2.4096(13) \\ \mathrm{Na} 1-\mathrm{O} 3 & 2.508(4) \\ \mathrm{S} 4-\mathrm{O} 5 & 1.4750(17) \\ \mathrm{Na} 1-\mathrm{O} 2-\mathrm{Na} 1^{\mathrm{i}} & 96.90(7) \\ \mathrm{O} 1-\mathrm{Na} 1-\mathrm{O} 2 & 96.06(4) \\ \mathrm{O} 1-\mathrm{Na} 1-\mathrm{O} 3 & 168.669(17) \\ \mathrm{O} 2-\mathrm{Na} 1-\mathrm{O} 3 & 92.41(4) \\ \mathrm{O} 2^{\mathrm{ii}}-\mathrm{Na} 1-\mathrm{O} 2 & 83.10(7) \\ \mathrm{O} 2^{\mathrm{iii}}-\mathrm{Na} 1-\mathrm{O} 2 & 167.88(7) \\ \mathrm{O}^{\mathrm{i}}-\mathrm{Na} 1-\mathrm{O} 2 & 95.62(7) \\ \mathrm{O}^{\mathrm{iii}}-\mathrm{Na} 1-\mathrm{O} 2 & 75.58(3) \\ \mathrm{O}^{\mathrm{ii}}-\mathrm{Na} 1-\mathrm{O} 3 & 92.39(4) \\ \mathrm{O}^{2 \mathrm{ii}}-\mathrm{Na} 1-\mathrm{O} 3 & 75.60(3) \\ \mathrm{Na}^{1}-\mathrm{O} 3-\mathrm{O} 3^{\mathrm{iv}} & 78.698(17) \\ \mathrm{O}^{\mathrm{v}}-\mathrm{S} 4-\mathrm{O} 5 & 109.24(7) \\ \mathrm{O}^{\mathrm{vi}}-\mathrm{S} 4-\mathrm{O} 5 & 109.93(14)\end{array}$

${ }^{a}$ Symmetry operations: (i) $2-x, 1-y, 1-z$; (ii) $2-x, y$, $z$; (iii) $2-x, 3 / 2-y, z$; (iv) $x, 3 / 2-y, z$; (v) $y-1 / 4,5 / 4-x, 3 / 4-z$; (vi) $1-$ $x, 3 / 2-y, z$.

Station 16.2 at the SRS Daresbury Laboratory, U.K. The X-ray intensities for the heptahydrate were collected on a Bruker SMART APEX CCD diffractometer equipped with an Oxford CryostreamPlus low-temperature device operating at $150 \mathrm{~K} .{ }^{18}$ Data collection and processing for the high-pressure experiment used the procedures outlined by Dawson et al. ${ }^{19}$ The structures were solved by direct methods (SIR-92) ${ }^{20}$ and structural refinement was completed using CRYSTALS. $^{21}$

Analysis of the diffraction data obtained for the heptahydrate showed there to be weak reflections that corresponded to a doubling of the $a$-axis. Our observations are supported by previous powder diffraction studies where weak $2 a$ supercell reflections have also been observed. ${ }^{15}$ Structural solution using the supercell can proceed in space group $P \overline{4}$ and allows the refinement of two separate positions for the bridging oxygen (O1 in our structure). These atoms still show elongated anisotropic thermal parameters that may suggest further disorder. It is our conclusion that the model presented here $\left(I 4_{1} /\right.$ amd $)$ gives a true representation of the crystal structure of the heptahydrate. There is disorder present in both models; however, the diffraction data pertaining to the supercell are rather weak and hence gives an unsatisfactory $R$-factor compared with that of the smaller unit cell $(R$-factor $=9.34 \%$ for $I>2 \sigma(I))$.

$\mathrm{Na}_{2} \mathrm{SO}_{4} \cdot 7 \mathrm{H}_{2} \mathrm{O}$ at 150 K. $M=268.15$, tetragonal, space group $I 4_{1} /$ amd $, a=7.1413(2), c=22.1101(11) \AA, V=1127.57(7) \AA^{3}$, $\rho_{\text {calcd }}=1.568 \mathrm{Mg} / \mathrm{m}^{3}$, crystal size $0.3 \times 0.3 \times 0.5 \mathrm{~mm}^{3}, T=150(2)$ $\mathrm{K}, Z=4$, GOF on $F^{2}=1.0089$. Final $R$ indexes $(I>2 \sigma(I)): R 1$ $=0.0410, w R 2=0.1190$ (6163 reflections, 453 unique, 30 parameters).

$\mathrm{Na}_{2} \mathrm{SO}_{4} \cdot \mathbf{7} \mathrm{H}_{2} \mathrm{O}$ at $277 \mathrm{~K} . M=268.15$, tetragonal, space group I4 ${ }_{1}$ /amd, $a=7.1554(2), c=22.2061(11) \AA, V=1136.95(7) \AA^{3}$, $\rho_{\text {calcd }}=1.555 \mathrm{Mg} / \mathrm{m}^{3}$, crystal size $0.3 \times 0.3 \times 0.5 \mathrm{~mm}^{3}, T=277(2)$ $\mathrm{K}, Z=4$, GOF on $F^{2}=1.0446$. Final $R$ indexes $(I>2 \sigma(I)): R 1$ $=0.0437,{ }_{\mathrm{w}} R 2=0.1150(6514$ reflections, 459 unique, 30 parameters). For selected bond lengths and angles please see $\mathrm{Ta}-$ ble 1.

$\mathrm{Na}_{2} \mathrm{SO}_{4} \cdot \mathbf{8} \mathrm{H}_{2} \mathbf{O} . M=286.17$, triclinic, space group $P \overline{1}, a=$ 7.8865(14), $b=8.096(8), c=8.2521(13) \AA, \alpha=85.73(3)^{\circ}, \beta$ $=86.239(15)^{\circ}, \gamma=88.59(3)^{\circ}, V=524.2(5) \AA^{3}, \rho_{\text {calcd }}=1.813$ $\mathrm{Mg} / \mathrm{m}^{3}$, crystal size $0.3 \times 0.15 \times 0.05 \mathrm{~mm}^{3}, T=293(2) \mathrm{K}, P$ $=1.54(5) \mathrm{GPa}, Z=2$, GOF on $F^{2}=0.9343$. Final $R$ indexes $(I$

(18) Cosier, J.; Glazer, A. M. J. Appl. Crystallogr. 1986, 19, 105-107.

(19) Dawson, A.; Allan, D. R.; Parsons, S.; Ruf, M. J. Appl. Crustallogr. 2004, 37, 410-416.

(20) Altomare, A.; Cascarano, G.; Giacovazzo, C.; Guagliardi, A. J. Appl. Crvstallogr. 1994, 27, 1045-1050.

(21) Betteridge, P. W.; Carruthers, J. R.; Cooper, R. I.; Prout, K.; Watkin, D. J. J. Appl. Crystallogr. 2003, 36, 1487.
Table 2. Selected Bond Lengths and Angles for Sodium Sulfate Octahydrate (Distances in $\AA$, Angles in deg) ${ }^{a}$

\begin{tabular}{|c|c|c|c|c|c|}
\hline $\mathrm{Na} 1-\mathrm{O} 1^{\mathrm{i}}$ & $2.402(6)$ & $\mathrm{O} 1-\mathrm{Na} 1-\mathrm{O} 2$ & $92.5(4)$ & $\mathrm{O} 7-\mathrm{Na} 3-\mathrm{O} 8$ & $104.4(5)$ \\
\hline $\mathrm{Na} 1-\mathrm{O} 2^{\mathrm{i}}$ & $2.381(16)$ & $\mathrm{O} 1^{\mathrm{i}}-\mathrm{Na} 1-\mathrm{O} 2$ & $87.5(4)$ & $\mathrm{O} 7-\mathrm{Na} 3-\mathrm{O} 9$ & $143.4(4)$ \\
\hline $\mathrm{Na} 1-\mathrm{O}^{\mathrm{i}}$ & $2.462(6)$ & $\mathrm{O} 1^{\mathrm{i}}-\mathrm{Na} 1-\mathrm{O} 3^{\mathrm{i}}$ & $80.70(19)$ & $\mathrm{O} 7-\mathrm{Na} 3-\mathrm{O} 10$ & $88.0(2)$ \\
\hline $\mathrm{Na} 2-\mathrm{O} 4$ & $2.301(10)$ & $\mathrm{O} 1-\mathrm{Na} 1-\mathrm{O} 3^{\mathrm{i}}$ & $99.30(19)$ & $\mathrm{O} 8-\mathrm{Na} 3-\mathrm{O} 4$ & $148.3(3)$ \\
\hline $\mathrm{Na} 2-\mathrm{O} 5$ & $2.376(11)$ & $\mathrm{O} 2-\mathrm{Na} 1-\mathrm{O} 3$ & $88.5(4)$ & $\mathrm{O} 8-\mathrm{Na} 3-\mathrm{O}^{\text {iii }}$ & $82.0(5)$ \\
\hline $\mathrm{Na} 2-\mathrm{O} 6$ & $2.546(12)$ & $\mathrm{O} 22^{\mathrm{i}}-\mathrm{Na} 1-\mathrm{O} 3$ & $91.5(4)$ & $\mathrm{O} 8-\mathrm{Na} 3-\mathrm{O} 9$ & $99.0(5)$ \\
\hline $\mathrm{Na} 3-\mathrm{O} 7$ & $2.350(6)$ & $\mathrm{Na} 2-\mathrm{O} 4-\mathrm{Na} 3$ & $109.1(4)$ & $\mathrm{O} 8-\mathrm{Na} 3-\mathrm{O} 10$ & $76.6(5)$ \\
\hline $\mathrm{Na} 3-\mathrm{O} 8$ & $2.38(2)$ & $\mathrm{O} 4-\mathrm{Na} 2-\mathrm{O} 5$ & $92.3(4)$ & $\mathrm{O} 9-\mathrm{Na} 3-\mathrm{O}^{\mathrm{iii}}$ & $79.2(3)$ \\
\hline $\mathrm{Na} 3-\mathrm{O} 9$ & $2.423(8)$ & $\mathrm{O} 4-\mathrm{Na} 2-\mathrm{O} 5^{\mathrm{ii}}$ & $87.7(4)$ & $\mathrm{O} 10-\mathrm{Na} 3-\mathrm{O} 9$ & $125.1(3)$ \\
\hline $\mathrm{Na} 3-\mathrm{O} 10$ & $2.423(7)$ & $\mathrm{O} 4-\mathrm{Na} 2-\mathrm{O} 6$ & $88.5(4)$ & $\mathrm{O} 10-\mathrm{Na} 3-\mathrm{O}^{\mathrm{iii}}$ & $149.6(6)$ \\
\hline $\mathrm{S} 11-\mathrm{O} 12$ & $1.478(7)$ & $\mathrm{O} 4-\mathrm{Na} 2-\mathrm{O}^{\mathrm{ii}}$ & $91.5(4)$ & $\mathrm{Na} 3^{\mathrm{iii}}-\mathrm{O} 7-\mathrm{S} 11$ & $126.5(4)$ \\
\hline \multirow[t]{8}{*}{$\mathrm{S} 11-\mathrm{O} 13$} & $1.503(8)$ & $\mathrm{O} 5-\mathrm{Na} 2-\mathrm{O} 6$ & $94.1(4)$ & $\mathrm{S} 11-\mathrm{O} 5-\mathrm{Na} 2$ & $129.3(4)$ \\
\hline & & $\mathrm{O} 5-\mathrm{Na} 2-\mathrm{O}^{\mathrm{ii}}$ & $85.9(4)$ & $\mathrm{S} 11-\mathrm{O} 7-\mathrm{Na} 3$ & $121.8(7)$ \\
\hline & & $\mathrm{Na} 33^{\mathrm{iii}}-\mathrm{O} 7-\mathrm{Na} 3$ & $103.3(3)$ & $\mathrm{O} 5-\mathrm{S} 11-\mathrm{O} 12$ & $109.9(8)$ \\
\hline & & $\mathrm{O} 4-\mathrm{Na} 3-\mathrm{O}^{\mathrm{iii}}$ & $127.1(5)$ & $\mathrm{O} 5-\mathrm{S} 11-\mathrm{O} 13$ & $109.7(6)$ \\
\hline & & $\mathrm{O} 4-\mathrm{Na} 3-\mathrm{O} 9$ & $77.7(5)$ & $\mathrm{O} 7-\mathrm{S} 11-\mathrm{O} 5$ & $111.0(6)$ \\
\hline & & $\mathrm{O} 4-\mathrm{Na} 3-\mathrm{O} 10$ & $79.9(5)$ & $\mathrm{O} 7-\mathrm{S} 11-\mathrm{O} 12$ & $110.0(6)$ \\
\hline & & $\mathrm{O} 7-\mathrm{Na} 3-\mathrm{O} 4$ & $95.6(4)$ & $\mathrm{O} 7-\mathrm{S} 11-\mathrm{O} 13$ & $107.6(8)$ \\
\hline & & $\mathrm{O} 7-\mathrm{Na} 3-\mathrm{O} 7^{\mathrm{iii}}$ & $76.7(3)$ & $\mathrm{O} 12-\mathrm{S} 11-\mathrm{O} 13$ & $108.6(4)$ \\
\hline
\end{tabular}

${ }^{a}$ Symmetry operations: (i) $-x,-y,-z$; (ii) $1-x,-y, 1-z$; (iii) 1 $-x, 1-y, 1-z$.

$>2 \sigma(I)): R 1=0.0725, \mathrm{w} R 2=0.2018$ (2222 reflections, 519 unique, 59 parameters). For selected bond lengths and angles please see Table 2 .

Neutron Powder Diffraction. High-pressure neutron powder diffraction data were collected using the PEARL/HiPr diffractometer at the ISIS spallation neutron source located at the STFC Rutherford Appleton Laboratory, U.K.

An aqueous solution (ca. $\left.0.1 \mathrm{~cm}^{3}\right)$ of sodium sulfate $(3.41 \mathrm{~mol} /$ $\mathrm{kg}$ water) in $\mathrm{D}_{2} \mathrm{O}$ was loaded into an encapsulated TiZr gasket ${ }^{22}$ together with a small quantity of lead to act as a pressure calibrant. ${ }^{23}$ The resulting capsule assembly was then compressed within a type V3b Paris-Edinburgh (P-E) press $^{24}$ to $2.4 \mathrm{GPa}$, and neutron powder diffraction patterns of ice-VII were recorded over the pressure range 2.4-3.0 GPa at a temperature of $291(0.5) \mathrm{K}$. On decompression to $\sim 0.1 \mathrm{GPa}$ the diffraction pattern of mirabilite (coexisting with the saturated solution) was observed indicating crystallization from the solution. Diffraction patterns were collected over $3 \mathrm{~h}$ periods at pressures of $0.1 \mathrm{GPa}$ up to $0.4 \mathrm{GPa}$, by which point the intensities of the Bragg peaks had become very weak.

\section{Results and discussion}

All attempts to obtain, isolate, and protect a single crystal of the heptahydrate suitable for single crystal X-ray diffraction were unsuccessful. Various strategies were attempted, including coating the crystal in oil and flash-cooling, but invariably any form of manipulation caused destruction of the crystal via rapid transformation to mirabilite. For this reason we opted to grow a single crystal of the heptahydrate from solution in a thinwalled glass capillary mounted on the diffractometer. This in situ technique has been widely used by several groups for growing single crystals of low-melting compounds from the pure liquid, ${ }^{25}$ but in situ crystal growth from solution is much less common and more challenging. It was particularly important when attempting to grow crystals of the metastable heptahydrate that all potential seed crystallites of more stable forms were completely dissolved by careful warming of the capillary. After

(22) Marshall, W. G.; Francis, D. J. J. Appl. Crystallogr. 2002, 35, 122.

(23) Fortes, D. Computational and Experimental Studies of Solids in the Ammonia-Water System. Ph.D. Thesis. Department of Earth Sciences, University College, University of London, 2004.

(24) Besson, J. M.; Nelmes, R. J.; Hamel, G.; Loveday, J. S.; Weill, G.; Hull, S. Phys. B 1992, 180-181, 907.

(25) (a) Boese, R.; Blaser, D.; Nussbaumer, M.; Krygowski, T. M. Struct. Chem. 1992, 3, 363-368. (b) Konietzny, S.; Fleischer, H.; Parsons, S.; Pulham, C. R. J. Chem. Soc., Dalton Trans. 2001, 3, 304-308. 


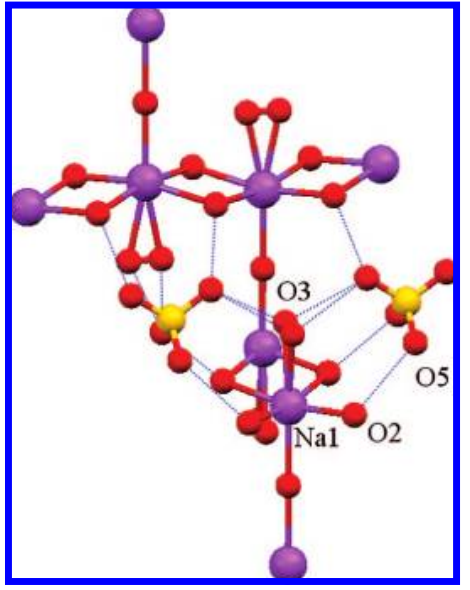

Figure 1. The crystal structure of $\mathrm{Na}_{2} \mathrm{SO}_{4} \cdot 7 \mathrm{H}_{2} \mathrm{O}$ viewed along the $a$-axis showing the 3-D network of octahedrally bound sodium ions, with sulfate ions hydrogen-bonded to water molecules. Hydrogen atoms have been omitted for clarity. Color scheme: sodium, purple; oxygen, red; sulfur, yellow.

controlled temperature cycling, a single crystal was grown in the capillary and was indexed to a tetragonal unit cell with similar dimensions to those found in the powder diffraction experiment. ${ }^{15}$ The structure was solved using direct methods and its identity was confirmed unequivocally as the elusive heptahydrate. The crystal structure (Figure 1) shows that each sodium cation is octahedrally coordinated to water molecules, with a slight distortion due to the oxygen atom $(\mathrm{O} 3)$ of one of the water molecules being disordered over two half-occupied sites. This disordered water molecule is the only one not involved in bridging to another sodium cation, but instead donates hydrogen bonds to two adjacent sulfate groups. The remaining five $\mathrm{Na}$-coordinated water molecules are involved, by either corner- or edge-sharing, in connecting neighboring $\mathrm{Na}$ cations to form a three-dimensional bonded network, in addition to acting as hydrogen-bond donors to the sulfate ion.

The sodium cations situated at $c=0$ and $1 / 2$ form chains along the $b$-direction and those at $c=1 / 4$ and $3 / 4$ form chains along the $a$-direction. The perpendicular chains are connected through a linearly bridging water molecule (O1). As with mirabilite, the sulfate ions are not directly bound to sodium ions, but instead accept hydrogen bonds from water molecules (Figure 2). ${ }^{26,27}$ The 3-D bonded network of the heptahydrate is in marked contrast to the 1-D bonded chains observed in mirabilite and so this major structural difference would explain the reconstructive nature of the transition between the heptahydrate and mirabilite. Observations on larger single crystals (ca. $1 \mathrm{~mm}$ ) show the phase transition from heptahydrate to mirabilite is pseudomorphic..$^{4 \mathrm{e}}$ The overall shape of the heptahydrate crystal is preserved but the pseudomorph is composed of smaller, rather anhedral crystals of mirabilite. These observations are similar to those reported by de Marignac. ${ }^{28}$

In addition to the experiments conducted using a capillary, we also attempted to crystallize the aqueous solution of sodium sulfate under high-pressure conditions. Past experience has shown that high-pressure crystallization from solution is a powerful technique for generating metastable solid forms.

(26) Levy, A. H.; Lisensky, G. C. Acta Crystallogr. 1978, B34, 35023510 .

(27) Brand, H. E. A.; Fortes, A. D.; Wood, I. G.; Knight, K. S.; Vočadlo, L. Phys. Chem. Min. 2008, doi: 10.1007/s00269-008-256-0.

(28) De Marignac, J. C. G. Ann. Mines 1857, 12, 1-74.

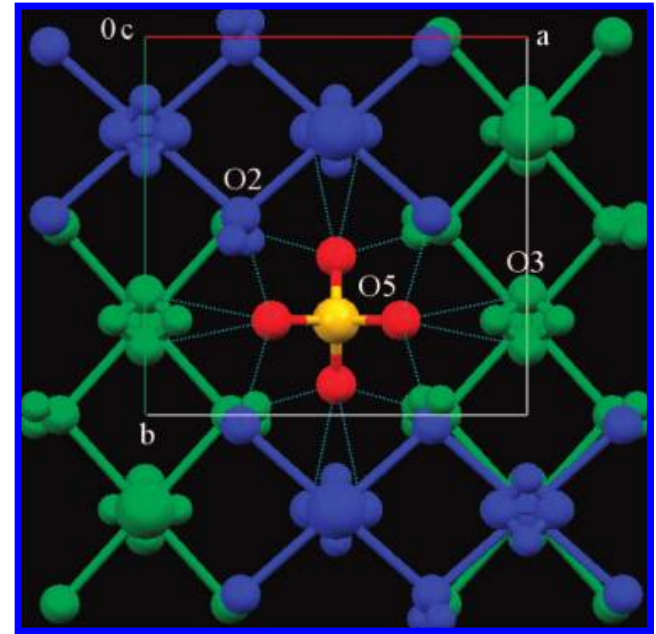

Figure 2. The crystal structure of $\mathrm{Na}_{2} \mathrm{SO}_{4} \cdot 7 \mathrm{H}_{2} \mathrm{O}$ viewed along $c$-axis showing the hydrogen-bonded sulfate groups. The blue chains are at $c=$ $1 / 4$ and the green chains are at $c=1 / 2$. Color scheme for the sulfate group: oxygen, red; sulfur, yellow.

Examples include new polymorphs of polycyclic hydrocarbons ${ }^{29}$ and pharmaceutical compounds, ${ }^{30}$ solvates of paracetamol, ${ }^{31}$ and a new hydrate of sodium formate. ${ }^{32}$ Crystallization at elevated pressure alters the relative thermodynamic stabilities of solid forms $^{33}$ and new phases may be structurally characterized in situ using a Merrill-Bassett diamond-anvil cell (DAC). Hence it was anticipated that this strategy might also provide a convenient route to the elusive heptahydrate. On loading an aqueous solution of sodium sulfate $(3.41 \mathrm{~mol} / \mathrm{kg}$ water $)$ into a DAC and pressurizing to $1.54 \mathrm{GPa}$ precipitation of polycrystalline material occurred. It proved possible to grow a rod-shaped single crystal by temperature cycling around $373 \mathrm{~K}$. Single crystal X-ray diffraction experiments identified this as a new triclinic phase with cell dimensions $a=7.8865(14), b=$ 8.096(8), $c=8.2521(13) \AA, \alpha=85.73(3)^{\circ}, \beta=86.239(15)^{\circ}$, $\gamma=88.59(3)^{\circ}, V=524.2(5) \AA^{3}$. The structure was solved using direct methods and this new phase was identified as sodium sulfate octahydrate. Attempts to recover the crystal to ambient pressure were unsuccessful, as even a slight decrease in pressure at ambient temperature caused the crystal to dissolve. However, it is of course possible that the pressure-stability range of the octahydrate could be extended by substantially reducing the temperature.

The crystal structure of the octahydrate (see Figure 3 for numbering scheme) is particularly interesting as the octahedrally water-coordinated sodium ions (Na1) sit at the corners of the unit cell to form a lattice that is somewhat reminiscent of a host framework (Figure 4). The other two sodium ions (Na2 and $\mathrm{Na} 3$ ) are connected through bridging water molecules (O4)

(29) Fabbiani, F. P. A.; Allan, D. R.; Parsons, S.; Pulham, C. R. Acta Crystallogr. 2006, B62, 826-842.

(30) Fabbiani, F. P. A.; Pulham, C. R.; Allan, D. R.; David, W. I. F.; Davidson, A. J.; Lennie, A. R.; Parsons, S.; Pulham, C.R.; Warren, J. E. Cryst. Growth Des. 2007, 7, 1115-1124.

(31) (a) Fabbiani, F. P. A.; Allan, D. R.; Dawson, A.; D.; David, W. I. F.; McGregor, P. A.; Oswald, I. D. H.; Parsons, S. Chem. Commun. 2003, 24, 3004-3005. (b) Fabbiani, F. P. A.; Allan, D. R.; David, W. I. F.; Moggach, S. A.; Parsons, S.; Pulham, C. R. CrustEngComm. 2004, 6, 504-511.

(32) Morrison, C. A.; Walker, M.; Allan, D. R.; Marshall, W. G.; Pulham, C. R. J. Chem. Soc., Dalton Trans. 2007, 20, 2014-2019.

(33) Ledru, J.; Imrie, C. T.; Pulham, C. R.; Céolin, R.; Hutchinson, J. M. J. Pharm. Sci. 2007, 96, 2784-2794. 


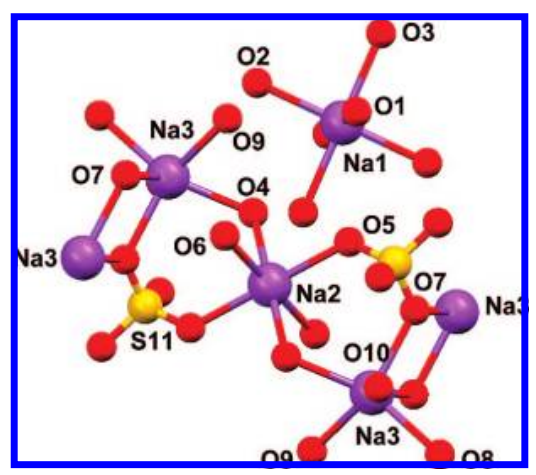

Figure 3. Numbering scheme for $\mathrm{Na}_{2} \mathrm{SO}_{4} \cdot 8 \mathrm{H}_{2} \mathrm{O}$. Color scheme: sodium, purple; oxygen, red; sulfur, yellow.

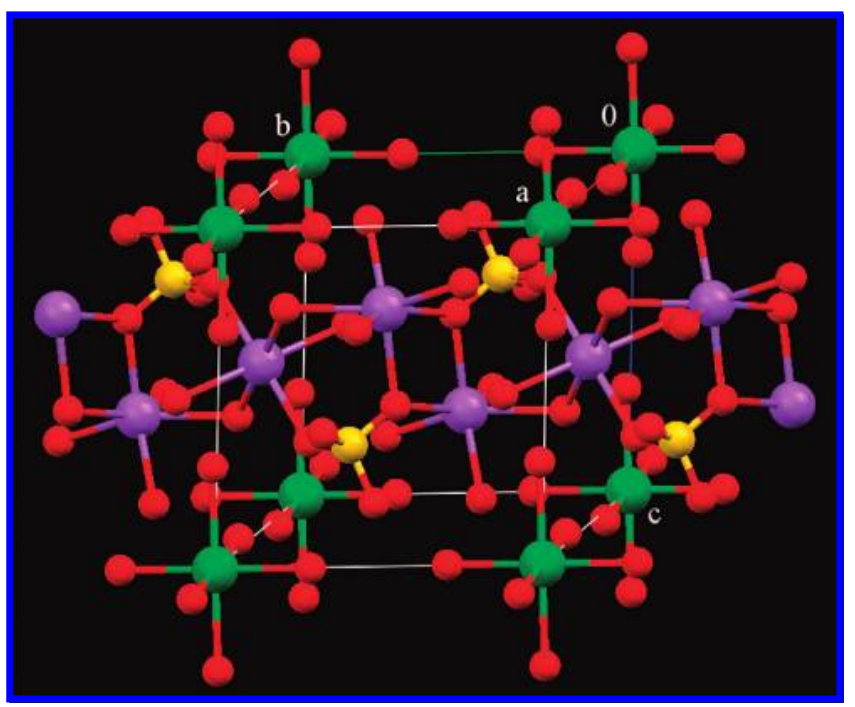

Figure 4. Crystal structure of $\mathrm{Na}_{2} \mathrm{SO}_{4} \cdot 8 \mathrm{H}_{2} \mathrm{O}$ showing sodium ions (in green) octahedrally coordinated by water molecules sitting at the corners of the unit cell to form the host lattice, with chains of sodium ions (in purple) linked by sulfate ions and water molecules to form chains that run through the host structure along the $b$-direction. Hydrogen atoms have been omitted for clarity. Color scheme: sodium, purple and green; oxygen, red; sulfur, yellow.

and sulfate ions $(\mathrm{O} 5-\mathrm{S} 11-\mathrm{O} 7)$ to form chains that run through the "host" structure along the $b$-direction. Both sodium ions are octahedrally coordinated by two sulfate ions and four water molecules. Na3 sits in a general position close to an inversion center with the sulfate groups bridging two symmetrically equivalent sodium ions. This bridging causes a distortion of the octahedral geometry so that the $\mathrm{O} 7-\mathrm{Na} 3-\mathrm{O} 4$ angle is increased to $127^{\circ}$ and the $\mathrm{O} 4-\mathrm{Na} 2-\mathrm{O} 10$ angle is reduced to $79^{\circ}$. One particularly striking feature of this structure is that the sulfate ions are coordinated directly to sodium ions. This is in contrast to both the heptahydrate and the decahydrate in which the sodium ions are coordinated exclusively by water molecules. Indeed, the higher hydrates of most metal sulfates (i.e., where the number of moles of water per metal ion $\geq 6$ ) adopt structures in which the metal ions are coordinated by water molecules rather than sulfate ions, for example, $\mathrm{MgSO}_{4} \cdot 7 \mathrm{H}_{2} \mathrm{O}$ and $\mathrm{MgSO}_{4} \cdot 11 \mathrm{H}_{2} \mathrm{O}{ }^{34}$ Exceptions are of course found for the hydrated sulfates of the lanthanides and actinides on account of the higher coordination numbers of these ions. Thus the

(34) Fortes, A. D.; Wood, I. G.; Knight, K. S. Phvs. Chem. Min. 2008, 35, 207-221. normal preference for coordination of sodium ions by $\mathrm{H}_{2} \mathrm{O}$ rather than $\mathrm{SO}_{4}{ }^{2-}$ is overturned in the high-pressure structure of $\mathrm{Na}_{2} \mathrm{SO}_{4} \cdot 8 \mathrm{H}_{2} \mathrm{O}$. This is presumably a consequence of the more efficient packing induced at high pressure and is achieved by sulfate ions bridging neighboring sodium ions. It illustrates how the hierarchies of interionic and intermolecular interactions can be significantly altered by high pressures. This finding suggests that there may be opportunities for pressure-tuning the affinities of ligands for cations, with potential applications in metal extraction processes at high pressures.

Ohno et al. have investigated microinclusions found in Antarctic ice cores obtained from Dome Fuji using Raman spectroscopy. ${ }^{3 \mathrm{~b}}$ The authors identified $\mathrm{Na}_{2} \mathrm{SO}_{4} \cdot 10 \mathrm{H}_{2} \mathrm{O}$ as a main component at most depths of ice, but at the greatest depth of ice sampled $(2413 \mathrm{~m})$ they found a sudden decrease in the content of the decahydrate. At this depth a new Raman band was observed at $984 \mathrm{~cm}^{-1}$, which was attributed to an unidentified sulfate. The authors speculated that this unidentified sulfate was $\mathrm{Na}_{2} \mathrm{SO}_{4} \cdot 10 \mathrm{H}_{2} \mathrm{O}$ that had changed into another phase due to the high pressures of the ice load. ${ }^{3 \mathrm{~b}}$ Given the very modest pressures induced by this depth of ice ( $\sim 240 \mathrm{~atm})$ and the very limited field of stability that we have found for the octahydrate, it seems very unlikely that the observed microinclusion was the high-pressure octahydrate. On the other hand, the Raman spectrum we have recorded for the heptahydrate showed a prominent band at $986 \mathrm{~cm}^{-1}$, in addition to a much weaker band at $466 \mathrm{~cm}^{-1}$. Although this spectrum has some similarities with that reported for the microinclusion, there remain sufficient differences to prevent an unequivocal identification. In particular, uncertainties in sampling conditions and the potential effects of both pressure and temperature on the positions of Raman bands make comparisons difficult. Nevertheless, given the conditions under which the heptahydrate is known to form, it is possible that inclusions of the heptahydrate might be found in deep ice cores.

In our high-pressure experiments we also investigated qualitatively the effects of pressure on the solubilities of both mirabilite and the octahydrate. Using neutron powder diffraction we observed a decrease in the intensities of the Bragg peaks from a sample of $\mathrm{Na}_{2} \mathrm{SO}_{4} \cdot 10 \mathrm{D}_{2} \mathrm{O}$ in $\mathrm{D}_{2} \mathrm{O}$ on application of pressures up to $0.4 \mathrm{GPa}$. At these low pressures, under hydrostatic and stable temperature conditions one would not expect pressure-induced broadening, and so this indicates that the solubility of the decahydrate increases over this pressure range. This is in agreement with earlier published work. ${ }^{35}$ Indeed, calculations on the pressure dependence of mirabilite solubility in water using FREZCHEM ${ }^{36}$ confirm that there is a $44 \%$ increase in solubility from 1 to 1000 bar at a constant temperature of $278 \mathrm{~K}$.

Attempts to crystallize $\mathrm{Na}_{2} \mathrm{SO}_{4} \cdot 8 \mathrm{H}_{2} \mathrm{O}$ in a diamond-anvil cell at higher pressures $(1.6-2.4 \mathrm{GPa})$ resulted instead in the production of a polycrystalline powder from which, after careful temperature-cycling, a single crystal of ice-VII was grown and subsequently identified by single crystal X-ray diffraction. This again illustrates the very narrow field of stability of the octahydrate. A recent paper reported the pressure-induced crystallization of the $\mathrm{NaCl}-\mathrm{H}_{2} \mathrm{O}$ system up to $28 \mathrm{GPa}$ and on the basis of $\mathrm{X}$-ray powder diffraction measurements suggested

(35) Dougherty, A. J.; Hogenboom, D. L.; Kargel, J. S.; Zheng, Y. F. Abstract No. 1732; 37th Annual Lunar and Planetary Science Conference; March 13-17, 2006; League City, TX.

(36) Marion, G. M.; Kargel, J. S.; Catling, D. C.; Jakubowski, S. D. Geochim. Cosmochim. Acta 2005, 69, 259-274. 
that the ice-VII that formed under these conditions had a higher density and bulk modulus than ice-VII formed from pure water over the pressure range $2.7-27 \mathrm{GPa} .{ }^{37}$ The authors also reported differences in the $\mathrm{O}-\mathrm{H}$ stretching modes and attributed these observations to incorporation of $\mathrm{Na}^{+}$and $\mathrm{Cl}^{-}$into the bodycentered cubic structure of ice-VII. To discover whether the $\mathrm{Na}_{2} \mathrm{SO}_{4}-\mathrm{H}_{2} \mathrm{O}$ system behaved in a similar way, we compressed a $3.41 \mathrm{~mol} / \mathrm{kg}$ water solution of $\mathrm{Na}_{2} \mathrm{SO}_{4}$ in $\mathrm{D}_{2} \mathrm{O}$ to produce iceVII at $2.4 \mathrm{GPa}$ and recorded the neutron powder diffraction patterns over the pressure range 2.4-3.0 GPa. Comparison with reference patterns of ice-VII formed from pure $\mathrm{D}_{2} \mathrm{O}$ showed no differences in density over this pressure range, and so we conclude that the $\mathrm{Na}_{2} \mathrm{SO}_{4}-\mathrm{D}_{2} \mathrm{O}$ system does not behave in the same way as the $\mathrm{NaCl}-\mathrm{H}_{2} \mathrm{O}$ system.

\section{Conclusions}

In summary, we have structurally characterized the elusive heptahydrate of sodium sulfate, an important intermediate phase in the crystallization of sodium sulfate solutions, and also a previously unknown octahydrate formed under high-pressure conditions. The success of the methods used to obtain these metastable forms reflects the confined nature of both the sealed capillary and the diamond-anvil cell. Both provide an environment in which it is possible to not only exclude atmospheric seed crystallites of more stable forms but also ensure that any remaining seed crystallites in solution can be completely

(37) Frank, M. R.; Runge, C. E.; Scott, H. P.; Maglio, S. J.; Olson, J. Prakapenka, V. B.; Shen, G. Phvs. Earth Planet. Inter. 2006, 155 , 152-162. dissolved. Such a strategy is crucial in view of the welldocumented difficulties experienced in crystallization processes, where the presence of even trace amounts of a more stable form in the atmosphere or on laboratory glassware may prevent the crystallization of the metastable form. ${ }^{38}$ The emerging rich hydrate structural chemistry of sodium sulfate contrasts with the other group 1 sulfates-only $\mathrm{Li}_{2} \mathrm{SO}_{4}$ has a monohydrate which has been identified and structurally characterized. ${ }^{39}$ Clearly the use of in situ techniques to search for new metastable and exotic forms that may occur in natural processes is an area ripe for exploration.

Acknowledgment. We would like to thank, in particular, one of the referees for their careful review of our manuscript and their suggestions for improvement. We would also like to thank Simon Parsons for helpful discussions. We also thank the Leverhulme Trust for a postdoctoral fellowship (I.D.H.O.), EPSRC for financial support (A.H.), and the U.K. STFC for provision of beamtime.

Supporting Information Available: Supplementary crystallographic data (cif). This material is available free of charge via the Internet at http://pubs.acs.org. Crystal Structure Depot at FIZ Karlsruhe, Germany, contains the crystallographic data: http://www.fiz-karlsruhe.de/obtaining_crystal_structure_data. html.

\section{JA805429M}

(38) Dunitz, J. D.; Bernstein, J. Acc. Chem. Res. 1995, 28, 193-200.

(39) Smith, H. G.; Peterson, S. W.; Levy, H. A. J. Chem. Phys. 1968, 48, $5561-5565$. 